\title{
O GENERAL DE MARX: O PENSAMENTO MILITAR DE FRIEDRICH ENGELS
}

\section{EL GENERAL DE MARX: EL PENSAMIENTO MILITAR DE FRIEDRICH ENGELS}

\section{MARX'S GENERAL: THE MILITARY THOUGHT OF FRIEDRICH ENGELS}

\author{
DOI: http://dx.doi.org/10.9771/gmed.v12i3.41927
}

João Rafael Chió Serra Carvalho ${ }^{1}$

Resumo: A obra militar engelsiana sempre foi considerada, mesmo entre seus detratores, uma das mais importantes, senão a mais importante, contribuição ao campo dos estudos militares no século XIX. No presente estudo tentaremos traçar os nortes gerais do que torna a contribuição de Friedrich Engels a esse campo a um só tempo tão frutífera e tão perene. Para tanto buscaremos analisar suas principais caraterísticas e contributos em uma perspectiva histórica para traçarmos um panorama geral dos estudos daquele que viria a ser alcunhado O General de Marx.

Palavras Chave: Friedrich Engels, Pensamento Militar

Resumen: El trabajo militar engeliano siempre ha sido considerado, incluso entre sus detractores, como uno de los aportes más importantes, si no el más importante, al campo de los estudios militares en el siglo XIX. En el presente estudio intentaremos trazar las pautas generales de lo que hace que la contribución de Friedrich Engels a este campo sea al mismo tiempo tan fructífera y tan perenne. Para esto, buscaremos analizar sus principales características y aportes en una perspectiva histórica con el fin de trazar un panorama general de los estudios de lo que vendría a denominarse El General de Marx.

Palabras clave: Friedrich Engels, Pensamiento militar

Abstract: Engels military work has always been considered, even among its detractors, as one of, if not the most important contribution to the field of military thought in the $19^{\text {th }}$ century. In the present article, we will try to outline the main characteristics that makes Engels' contributions to this field at once so productive and perennial. In that pursue we shall analyze its main traits and inputs in a historical perspective as to map a general outlook of the studies of the man which would be named Marx's General.

Keywords: Friedrich Engels, Military Thought

\section{Introdução}

O filósofo, sociólogo e cientista político francês Raymond Aron dedicou as seguintes palavras a Clausewitz, em sua obra sobre o grande teorista militar do século XVIII:

Parece que devemos os grandes livros sobre ação a homens de ação que o destino privou de sua maior realização, homens que chegaram a uma sutil mistura de engajamento e desapego que os deixou capazes de reconhecer as restrições e grilhões do soldado ou do político e também capazes de olhar de fora, não com indiferença, mas com calma, para a ironia do destino e para o jogo imprevisível de forças que nenhuma vontade pode controlar. (ARON, 1983, p.12)

Por sua vez, o professor Gilbert Achcar, ao se referir à citação acima, disse "Essas linhas, ... que Raymond Aron dedicou a Clausewitz e seus sucessores, poderiam ter sido escritas, palavra por palavra, sobre Friedrich Engels.” (ACHCAR, 2002, p.1). Fazemos nossas as palavras de Achcar. 
A reputação de Friedrich Engels nos circuitos acadêmicos formais, profundamente influenciados pelo estruturalismo, pós-estruturalismo 2 e "pós-modernismo"3, bem como sua influência naqueles círculos que Domenico Losurdo chamou de "marxismo ocidental”, nos últimos cinquenta anos, enquanto teórico social e político, sofreu ataques tão profundos quanto aqueles que o próprio marxismo viria a sofrer neste período.

Não obstante, mesmo entre seus detratores ${ }^{5}$, seus escritos militares continuam a ser considerados em alta estima. ${ }^{6}$ No que tange à literatura militar especializada, a obra de Engels é tão louvada quanto a de Clausewitz. W. B. Gallie argumenta que Engels "tornou-se provavelmente o mais arguto crítico militar do século XIX" (GALLIE, 1978, p.68), Neumann e Von Hagen afirmam "Ele é um gênio da crítica. Seus julgamentos são tão pesados e tão valiosos quanto ouro. Ele demonstra como a grandeza no pensamento estratégico consiste na simplicidade" (NEUMANN, VON HAGEN apud PARET, 1986, p.25). Berger vai ainda além e afirma de forma irônica "...em uma história do século XIX compilada por um fanático militar, Marx não seria senão o assistente de pesquisas de Engels" (BERGER, 1977, p.50).

Esta visão, que encara Engels como um arguto e profícuo intelectual dos assuntos militares e desconsidera sua obra política como de menor monta, é uma deturpação idealista e liberal de Engels que subtrai ao pai do socialismo científico precisamente o seu método de concepção e compreensão do mundo. Ora, para Engels, sua obra militar e sua obra política não são cingidas, antes pelo contrário formam uma totalidade que deve ser compreendida como uma interpretação, a um só tempo socialista e científica, voltada a traçar, a partir da teoria, uma prática ${ }^{7}$ de como poderia o socialismo triunfar contra um capitalismo internacional que era uma totalidade concreta fixada por meio de poderes legais, ideológicos e militares que competiam entre si. Para entendermos os principais nortes desta obra é preciso que agora nos detenhamos um pouco sobre o caminho traçado pelo próprio Engels.

\section{O Homem e a Caserna: a vivência militar e a formação teórica de Engels}

Aos 21 anos de idade, em 1841 o jovem Friedrich Engels se alistou como voluntário, pelo período de um ano, no Exército da Prússia, sendo designado a servir na Garde-Artillerie-Brigade ${ }^{8}$ em Berlim. Durante esse ano como brigadista - Engels seria dispensado com honras em Outubro de 1842 - o jovem intelectual ganhou acesso ao ciclo dos Livres, grupo de Jovem Hegelianos berlinenses capitaneado por Bruno Bauer ${ }^{9}$ devido a seus trabalhos apócrifos sobre o pseudônimo de Friedrich Oswald nos quais tecia duras críticas à religião ${ }^{10}$.

Em 1842, após sua baixa do Exército, Engels foi enviado por seus pais para Manchester, na Inglaterra, um centro manufatureiro onde a industrialização estava em ascensão, onde deveria trabalhar nos escritórios da Ermen and Engels Victoria Mill. Seu pai, um dos acionistas do empreendimento, pensou que trabalhar na empresa da família em Manchester pudesse levar seu filho a reconsiderar algumas de suas opiniões mais radicais ${ }^{11}$. Em seu caminho para Manchester, Engels visitou o escritório do Rheinische Zeitung12 em Colônia e encontrou-se com Karl Marx pela primeira vez. O encontro foi breve e frio. Marx erroneamente pensou que Engels ainda estava associado aos berlinenses, grupo de jovens hegelianos, com 
quem Marx havia acabado de romper laços. ${ }^{13}$ Apesar de ainda não se tornarem amigos, já se tornaram camaradas de luta e Engels vai para a Inglaterra como correspondente internacional da Rheinische.

Em Manchester, Engels conheceria Mary Burns com quem manteve um relacionamento que duraria até sua morte em 186314. Burns guiou Engels por Manchester e Salford, mostrando-lhe os piores distritos para sua pesquisa ${ }^{15}$. Enquanto em Manchester, entre outubro e novembro de 1843, Engels escreveu seu primeiro trabalho econômico, intitulado "Esboço de uma crítica da economia política"16. Engels enviou o artigo para Paris, onde Marx o publicou no Deutsch-Franæösische Jahrbücher ${ }^{17}$ em 1844.

Enquanto observava as precárias condições das moradias dos trabalhadores de Manchester em detalhes, Engels tomou nota de seus horrores, notadamente o trabalho infantil, o ambiente permeado pela pobreza e carestia onde existiam em vida nua ${ }^{18}$ trabalhadores sobrecarregados e empobrecidos. Ele enviou uma trilogia de artigos para Marx que foram publicados primeiro na Rheinische Zeitung e posteriormente no Deutsch-Franæösische Jabrbücher. Tais artigos viriam a compor seu livro A Situação da Classe Trabalhadora na Inglaterra.

Engels mantém em sua estada em Manchester um envolvimento contínuo com o jornalismo radical $^{19}$ e a política. Conheceu em profundidade as áreas de influência dos movimentos trabalhistas e cartistas com quem manteve profuso contato. Nesse período escreveria para vários jornais, incluindo o The Northern Star, periódico socialista ligado ao movimento cartista e o New Moral World de Robert Owen ${ }^{20}$.

Em 1844 Engels decide retornar à Alemanha. No caminho, ele passa por Paris onde se encontraria com Karl Marx, com quem mantinha correspondência desde o primeiro encontro na sede da Rheinische Zeitung. Por sua vez, Marx já estava em Paris desde outubro de 1843, devido ao fechamento do jornal em Colônia pelas autoridades governamentais prussianas e o clima de perseguição aos elementos mais avançados do movimento democrático e socialista que grassava na Prússia à época ${ }^{21}$. É importante ressaltar que, mesmo antes do encontro que mudaria a vida de ambos, bem como a história ulterior do século XIX e do movimento socialista e comunista mundial, Engels já havia se estabelecido como um socialista científico, independente do desenvolvimento filosófico de Marx.

Em Paris, Marx estava publicando o Deutsch-Franæösische Jahrbücher. Engels encontrou Marx pela segunda vez no Café de la Régence na Place du Palais, em 28 de agosto de 1844. Os dois logo se tornariam amigos íntimos e companheiros de luta e assim permaneceriam por toda uma vida. Marx havia se impressionado com a leitura dos artigos de Engels sobre as condições da classe trabalhadora na Inglaterra onde havia escrito:

“... Pode-se exigir de uma classe que suporta todos os inconvenientes da ordem social, sem se beneficiar de nenhuma de suas vantagens, pode-se exigir dela algum respeito para com essa ordem social, que necessariamente lhe parece como hostil? (ENGELS,2008, P.167)

É, portanto, de Engels, que Marx esposa a ideia de ser a classe trabalhadora quem lideraria a revolução contra a burguesia enquanto avançava a sociedade em direção ao socialismo. ${ }^{22}$

Engels permanece em Paris para colaborar com Marx na escrita de $A$ sagrada familia, um acerto de contas com os jovens hegelianos e os irmãos Bauer publicado em fevereiro de 1845. Em 6 de setembro de 
1844, Engels deixa Paris e volta para a casa de sua família em Barmen, Alemanha, onde terminaria seu $A$ Situação da Classe Trabalhadora na Inglaterra, publicado originalmente em maio de 1845. Antes mesmo da publicação de seu livro, Engels se muda para Bruxelas onde colaboraria com Marx na escrita da Ideologia Alemã. ${ }^{23}$

Durante sua estada em Paris, tanto Marx como Engels se juntaram à sociedade revolucionária secreta chamada Liga dos Justos. ${ }^{24}$ A Liga dos Justos havia sido formada em 1837 na França com o objetivo de promover uma sociedade igualitária com a derrocada revolucionária dos governos de então. Em 1839, a Liga participara da rebelião fomentada pelo socialista utópico revolucionário Louis Auguste Blanqui.

Mesmo tendo rompido com Ruge devido à sua manutenção na esfera de pensamento dos Jovens Hegelianos, Marx envia a Ruge um aviso que a polícia de Paris iria executar ordens contra ele e outros do Deutsch-Französische Jahrbücher exigindo que todos saíssem de Paris em 24 horas $^{25}$. O próprio Marx seria expulso de Paris pelas autoridades francesas em 3 de fevereiro de 1845, vindo a se estabelecer com sua esposa e uma filha em Bruxelas.

Enquanto vivia em Barmen, Engels começou a organizar uma rede de contatos com socialistas na Renânia, em um primeiro momento para arrecadar fundos para os esforços de publicação de Marx em Bruxelas $^{26}$. Tais contatos seriam imperiosos quando Marx e Engels começaram a organizar politicamente o Partido dos Trabalhadores Social-democratas da Alemanha ${ }^{27}$.

A Bélgica, recém fundada em 1830, possuía uma das mais liberais constituições de toda a Europa e era o refúgio de muitos progressistas. Entre 45 e 48, Marx e Engels viveram em Bruxelas, onde dedicariam a maior parte de seu tempo a organizar os trabalhadores alemães da cidade. Lá, se juntariam à Liga Comunista Alemã, a organização que sucedera a velha Liga dos Justos. Influenciada por Wilhelm Weitling, a Liga Comunista era uma sociedade internacional de revolucionários proletários com filiais em várias cidades europeias.

A Liga encarregou Marx e Engels da tarefa de escrever um breve panfleto explicando os princípios norteadores do comunismo. Tal se tornaria o mundialmente famoso Manifesto do Partido Comunista, mais conhecido como Manifesto Comunista ${ }^{28}$, publicado pela primeira vez em 21 de fevereiro de 1848 que inscreveria na história da humanidade seu mote revolucionário:

\begin{abstract}
Os comunistas se recusam a dissimular suas opiniões e seus fins. Proclamam abertamente que seus objetivos só podem ser alcançados pela derrubada violenta de toda a ordem social existente. Que as classes dominantes tremam à ideia de uma revolução comunista! Nela os proletários nada têm a perder a não ser seus grilhões. Têm um mundo a ganhar. Proletários de todos os países, uni-vos! (ENGELS, MARX, 1998, p.51)
\end{abstract}

Em 1848 eclode em França um processo revolucionário que rapidamente se espalharia como fogo selvagem para outros países da Europa Ocidental. Tais eventos levariam Engels e Marx a retornar à sua terra natal, a Prússia, especificamente à cidade de Colônia. Enquanto moraram em Colônia, eles criaram e trabalharam como editores para um novo periódico chamado Neue Rheinische Zeitung. Concomitante ao desenvolvimento da luta de classes na Alemanha, Engels escreveu uma série de relatórios sobre a Revolução e Guerra pela Independência da recém-fundada República Húngara ${ }^{29}$, seus artigos tornar-se-iam regulares 
no Neue Rheinische Zeitung. ${ }^{30}$ Entretanto, a gazeta seria suprimida durante o golpe de Estado prussiano de junho de 1849.

Marx teria sua cidadania prussiana cassada e sua deportação emitida após o golpe de Junho, sairia da Alemanha via Paris e depois para Londres. Entre 1848 e 1849 Engels se alistaria para lutar na revolução alemã, primeiro em sua própria cidade, Elberfeld, em maio de 49, da qual rapidamente seria expulso por medo que um "vermelho como ele pudesse contaminar o Comitê local de Segurança Pública." (ACHCAR, 2002, p.1)

Finalmente, em junho de 1849, Engels se somou às fileiras de um exército insurrecional para o levante revolucionário de Baden e Palatinado como ajudantes-de-ordens no corpo de voluntários de August Willich ${ }^{31}$. Engels e o grupo de Willich lutaram sua derradeira batalha nas cercanias de Kaiserslautern, quando a revolta foi esmagada, Engels foi um dos últimos a escapar cruzando a fronteira com a Suíça. ${ }^{32}$

Tão prontamente se considerou em segurança em solo suíço, Engels começou a escrever suas recordações da recente campanha militar contra os prussianos. Tal artigo seria publicado sob o nome de The campaign for the german imperial constitution ${ }^{33}$. Em julho de 1851, o pai de Engels chegou para visitá-lo em Manchester, na Inglaterra. Durante a visita, seu pai conseguiu que Engels se encontrasse com Peter Ermen, do escritório da Ermen \& Engels, para se mudar para Liverpool e assumir a gestão do escritório em Manchester. Em carta a Marx, Engels narra:

Caro Marx.... Depois de ficar por uma semana com meu velho, eu felizmente o mandei embora e hoje finalmente serei capaz de te enviar o pedido de correios incluso por 5 libras. No todo posso me declarar satisfeito com os resultados do meu encontro com o velho. Ele vai precisar de mim aqui por três anos, pelo menos, mas não entrei em nenhuma obrigação de longo prazo, nem mesmo por 3 anos, nem me fora solicitado nenhum compromisso tanto no que diz respeito à minha escrita ou à minha permanência aqui no caso de uma revolução (ENGELS, MARX, 1982, p.378)

Tal "breve compromisso" sem nenhuma "obrigação de longo prazo" acabaria por perdurar os próximos 19 anos da vida de Engels e seria por meio de seu trabalho na Ermen \& Engels que ele subsidiaria os escritos de Marx, a publicação de O capital, sua própria manutenção e boa parte das lutas que entrariam nas próximas décadas a um enorme custo pessoal. A partir de então, o General se recolhe a seu gabinete e será daí em diante que produzirá suas mais perenes contribuições com a história do pensamento militar comunista e da própria estratégia militar em geral.

\section{A Caserna e o Homem: Engels como pensador militar}

Os textos militares de Engels, que apesar de diversos esforços, ${ }^{34}$ nunca foram estudados em sua totalidade, lidam com todos os aspectos da ciência da guerra. Ele escreveu sobre questões de organização e armamento, sobre a evolução da arte da guerra durante a revolução industrial, sobre aspectos militares da política internacional, sobre estratégia e tática, bem como sobre questões de comando e qualidade dos generais. Da mesma maneira, ele formulou algumas previsões proféticas sobre a guerra futura, as quais de fato corresponderam à realidade da Primeira Guerra Mundial. 
Em seus escritos anônimos sobre a situação militar no oeste e no sudoeste da Europa, Engels traçou um plano que, 45 anos depois, receberia o nome de Schlieffen ${ }^{35}$. Ele mostrou por que tal plano alemão seria condenado ao fracasso em uma guerra contra a França. Ele anteviu com grande precisão a duração da guerra mundial que se aproximava, a escala das perdas e as condições que a levariam ao fim.

Assim como Clausewitz, a quem Engels tinha em grande estima, ele procurou não elaborar um sistema completo e uma doutrina abrangente da guerra, mas tão somente comentar sobre as guerras e as situações reais nas condições concretas das totalidades de seu desenvolvimento. Como poderia ele ter sido tentado por qualquer tipo de sistematização na doutrina militar quando estava constantemente enfatizando a aceleração vertiginosa do progresso da tecnologia militar, que produzia armamentos que por vezes estavam “desatualizado antes de ser lançado”?36

O principal interesse no pensamento de Engels sobre a guerra deve ser vislumbrado no tratamento dado aos problemas candentes para o movimento dos trabalhadores em relação às guerras, qual deva ser a atitude tomada em relação às guerras não revolucionárias, quais as articulações entre a guerra e a revolução e qual seria a possibilidade de uma estratégia para a revolução que não fosse dependente da guerra. É precisamente este foco que torna Engels, como teórico da guerra e estrategista da revolução socialista, ainda tão atual. De igual maneira foi neste sentido que seu pensamento sobre a guerra e a revolução antecipou diversas questões do século XX e provavelmente continuará a manter sua relevância e sua atualidade ainda por muito tempo.

Engels viveu sob a égide da conclusão da transformação burguesa na Europa, uma época em que o continente ainda estava se livrando de seu longo passado feudal e agrário. As guerras que experienciou foram principalmente a expressão dessa transformação. Tais guerras foram, ao menos em sua esmagadora maioria, guerras de conquista que prefiguraram a guerra de banditismo que seria a Primeira Guerra Mundial. Ele e Marx por vezes distinguiam, para o mesmo protagonista em uma mesma guerra, uma fase emancipatória que merece apoio passivo, senão ativo, e uma fase opressora em que se deve fazer causa comum com o lado oposto, mesmo se a política que ensejou o curso de tal guerra não mudou de forma significante no processo.

Tal característica afastam Engels e Marx enquanto teóricos militares da concepção clássica de Clausewitz, o qual afirma que "a guerra é a continuação da política por outros meios" (CLAUSEWITZ,1984, p.87). Para ambos o que importava não era a política da qual uma dada guerra era a continuação, mas, sobremaneira qual movimento histórico subjacente era ela a portadora. Para os pais fundadores do materialismo histórico, uma guerra não deveria ser julgada com base nas ideias políticas daqueles que a estavam travando. Seu julgamento, do ponto de vista de investigadores da estrutura socioeconômica, orientava-se pelo efeito objetivo da guerra sobre a libertação das forças produtivas dos entraves sociais ou políticos ao seu desenvolvimento.

Com o crescimento exponencial do movimento operário, sobretudo na Alemanha, Marx e Engels priorizaram como critério de mensuração o efeito da guerra sobre esse movimento, portador da emancipação final. É compreendendo tal critério que podemos vislumbrar a importância da anexação da Alsácia-Lorena para a ulterior consecução das possibilidades da revolução no centro da Europa. Essa 
anexação, de fato, abriu trincheiras entre os dois batalhões de choque do proletariado europeu, ao incitar o chauvinismo de ambos os lados. Trazia em si a possibilidade de uma nova guerra em que desta vez o resto da Europa poderia ser engolfado e na qual os trabalhadores de todas as terras se matariam uns aos outros.

É somente a partir dessa análise do rol de forças que podem ser desencadeadas por um conflito vindouro em todo o teatro europeu que podemos compreender a profundidade contida nos dois discursos do Conselho Geral da Associação Geral dos Trabalhadores sobre a Guerra Franco-Prussiana elaborados por Marx e Engels em Julho e Setembro de 1870:

Se a classe trabalhadora alemã permitir que a guerra atual perca seu caráter estritamente defensivo e degenere em uma guerra contra o povo francês, a vitória ou a derrota serão igualmente desastrosas. (ENGELS; MARX, 1986, p.6)

[...] após uma breve trégua, [a Alemanha terá que] se preparar novamente para outra guerra "defensiva", não uma daquelas guerras "localizadas" de última geração, mas uma guerra de raças - uma guerra com as raças combinadas dos Eslavos e dos Romanos. (ENGELS; MARX, 1986, p.267)

Ora, tendo em vista a corrida armamentista desencadeada pelo resultado do conflito de 1870 , bem como o crescimento dos meios de destruição em massa - aos quais Engels alude com tanta clareza em seu Anti-Dühring - a violência da guerra, que por vezes poderia atuar como parteira do progresso social, se tornava cada vez mais a rapsoda de sua elegia fúnebre.

Em outras palavras, mesmo que tal guerra conduzisse, mais ou menos no longo prazo, a uma transformação revolucionária, teria sido o pior meio de chegar lá. O preço seria um massacre terrível e uma destruição gigantesca das forças produtivas.

Obviamente Engels não foi o único pensador de sua geração a se alarmar com os acontecimentos europeus. Sua unicidade, aquilo que o torna diferente dos demais é, precisamente, o ferramental analítico usado para tal que desvela em sua totalidade o movimento do real. Ao se debruçar sobre sua realidade solidamente amparado com as armas da crítica, Engels pode fazer a crítica das armas com profunda clareza quase em tom de vaticínio. O dilema entre socialismo e barbárie torna patente na passagem abaixo:

E, finalmente, a única guerra que a Prússia-Alemanha travará será uma guerra mundial, uma guerra mundial, aliás, de uma extensão e violência até então inimagináveis. Oito a dez milhões de soldados lutarão uns contra os outros e, no processo, despirão a Europa mais do que um enxame de gafanhotos. As depredações da Guerra dos Trinta Anos se comprimiram em três a quatro anos e se estenderam por todo o continente; fome, doença, o colapso universal na barbárie, tanto dos exércitos quanto do povo, na esteira da miséria aguda; deslocamento irrecuperável de nosso sistema artificial de comércio, indústria e crédito, terminando em falência universal; o colapso dos velhos Estados e de sua sabedoria política convencional ao ponto em que as coroas rolarão para a sarjeta às dezenas e ninguém estará por perto para pegá-las; a absoluta impossibilidade de prever como tudo vai acabar e quem sairá vencedor da batalha. Só uma consequência é absolutamente certa: o esgotamento universal e a criação das condições para a vitória final da classe trabalhadora. Essa é a perspectiva para o momento em que o desenvolvimento sistemático do aperfeiçoamento mútuo em armamentos atinge seu clímax e finalmente produz seus frutos inevitáveis. (ENGELS; MARX, 1986, p.451)

A proficuidade dos acertos é avassaladora, as condições para eclosão da revolução no campo perdedor com a derrota de seus exércitos, o espalhamento do conflito, sua violência inaudita. Mas, para além daquilo que está escrito, devemos ler também, a contrapelo, aquilo sobre o que o texto silencia ${ }^{37}$. Tal guerra seria a prova cabal da falha dos partidos socialistas, as parcas vitórias seriam sobrepujadas pelo avanço 
triunfante da barbárie. Era preciso tentar para-la de todas as formas possíveis. É o que o próprio Engels advoga em carta a seu amigo Bebel datada de 1886:

Em suma, haverá o caos cujo único resultado certo será uma carnificina em massa em uma escala até então sem precedentes, o esgotamento de toda a Europa em um grau até então sem precedentes e, finalmente, o colapso completo do antigo sistema ... Uma vitória imediata para nós só poderia ser produzida por uma revolução na França ... Uma revolução na Alemanha após uma derrota seria de uso único se isso levasse à paz com a França. O melhor de tudo seria uma revolução russa que, no entanto, só pode ser esperada após severas derrotas infligidas ao exército russo ... Isso é certo: uma guerra iria, acima de tudo, retardar nosso movimento em toda a Europa, interrompê-lo completamente em muitos países, incitar o chauvinismo e a xenofobia, e nos deixar com a certa perspectiva, entre muitas outras incertas, de ter que começar tudo de novo depois da guerra, embora em bases muito mais favoráveis do que hoje. (ENGELS; MARX, 1995, p.487)

Se o prognóstico da carta de 1886 abre a esperança de uma revolução periférica na Rússia, em carta de 1889 Engels se debruça sobre o sombrio prognóstico para o movimento na Alemanha, mais uma vez mostrando quão profícuo é o materialismo científico na análise das totalidades do movimento do real:

Sobre a questão da guerra, é a mais terrível contingência para mim. Mas, por isso, eu não daria a mínima para os caprichos de Madame la France. Mas uma guerra que envolverá de 10 a 15 milhões de combatentes, uma devastação sem paralelo - apenas para alimentálos - a supressão compulsória e universal do nosso movimento, o recrudescimento do chauvinismo em todos os países e, no final, um enfraquecimento dez vezes pior do que depois de 1815, um período de reação baseado na inanição de todos os povos sangrados de branco - tudo isso contra a tênue esperança de que essa guerra feroz resulte em revolução - é isso que me horroriza. Sobretudo em relação ao nosso movimento na Alemanha, que seria esmagado pela violência, enquanto a paz garante a vitória quase certa. (ENGELS; LAFARGUE, 1960, p.210)

Destarte é a partir da aplicação consequente do método analítico dialético que Engels reverte, pós

1871, sua concepção sobre a guerra como fomentador da revolução. Não seria um chauvinismo rasteiro pró “alemão", tampouco qualquer preconceito contra outras nacionalidades, mas, sim, uma antecipação dos possíveis impactos de qualquer guerra real em sua vertente total sobre o potencial futuro do movimento operário europeu que levaria Engels a divisar um horizonte de tragédias e lutar pela consecução da revolução como meio de se evitar a guerra. ${ }^{38}$ Conforme resta explícito em correspondência com Bernstein:

Devemos cooperar no trabalho de libertar o proletariado da Europa Ocidental e subordinar tudo o mais a esse objetivo. Por mais interessantes que sejam os eslavos balcânicos, etc., no momento em que seu desejo de libertação colide com os interesses do proletariado, eles podem ser enforcados por mim. Os alsacianos também são oprimidos ..., Mas se, evidentemente, na própria véspera de uma revolução, eles tentassem provocar uma guerra entre a França e a Alemanha, mais uma vez incitando esses dois países e, assim, adiando a revolução, eu deveria dizer a eles: "Segure firme! Certamente você pode ter tanta paciência quanto o proletariado europeu. Quando eles se libertarem, você será automaticamente livre; mas até então, não permitiremos que você coloque um raio na roda do proletariado militante." O mesmo se aplica aos eslavos. A vitória do proletariado os libertará na realidade e por necessidade e não, como o czar, aparente e temporariamente ... para incitar uma guerra geral por causa de alguns herzegovinos, que custaria mil vezes mais vidas do que ali são habitantes da Herzegovina, não é essa minha ideia de política proletária. (ENGELS, MARX, 1992, p.205)

A escalada reacionária da década de 70 e o revanchismo alimentado no seio de boa parte do povo francês em relação aos desenvolvimentos do conflito franco-prussiano eram percebidos por Engels como um perigoso sinal no horizonte. Ademais, o massacre contra a Comuna de Paris levado a cabo por Versalhes 
enquanto as tropas alemãs apenas observavam retroalimentava o desidério pela revanche. Foi mais uma vez pensando no desenvolvimento global do movimento operário revolucionário que ele escreveria seu notório texto, Socialismo na Alemanha, no qual denunciou a anexação da Alsácia-Lorena, declarou sua preferência pela república burguesa francesa em relação ao Império Alemão, mas mesmo assim explicou que, em caso de aliança com a Rússia, a guerra contra a Alemanha só poderia ter um conteúdo reacionário. O socialismo alemão pagaria um preço altíssimo em caso de vitória russa, sendo esmagado ou pelo inimigo de fora ou, em última instância, pelo inimigo interno. ${ }^{39}$

Tal texto seria usado de forma arguta e vil pelo cadáver putrefato da socialdemocracia alemã ${ }^{40} \mathrm{em}$ 1914 como pretensa defesa de um argumento pela defesa patriótica. Ora, tal falso chauvinismo apostado contra a memória de Engels fora prontamente denunciado, primeiro por Rosa Luxemburgo em sua famosa Brochura de Junius ${ }^{41}$ e posteriormente por Zinoviev em seu panfleto de 1916 La II Internationale et le problème de la guerre: Renonçons-nous à notre béritage?42

Cônscio da necessidade de aliar teoria à prática material, Engels procurou em cada fronte possível preparar o terreno para a revolução proletária e, ao mesmo, refrear a vindoura guerra mundial. Na luta pela paz ele rejeitou as propostas idealistas e a fraseologia barata formulando sua demanda a um só tempo realista e revolucionária.

Sua proposta, publicada pela primeira vez em uma série de artigos no Vorwärts, foi condensada em um panfleto chamado Kann Europa abrüsten ${ }^{43}$, onde propôs a redução gradual do serviço militar por tratado internacional, visando a transformação dos exércitos permanentes em uma milícia baseada no armamento universal do povo:

Tento provar que essa transformação é possível neste exato momento, mesmo para os governos atuais e a situação política atual. Portanto, tomo essa situação como minha base e, por enquanto, proponho apenas os meios que poderiam ser adotados por qualquer governo da época sem comprometer a segurança nacional. Eu simplesmente procuro estabelecer que, de um ponto de vista puramente militar, não há barreiras para impedir a abolição gradual de exércitos permanentes; e que, se esses exércitos são mantidos, é por razões políticas e não militares - que, em uma palavra, os exércitos têm a intenção de proteger não tanto contra o inimigo externo mas contra o interno. (ENGELS; MARX, 1990, p.371)

A ideia por trás da proposta de Engels, que pode em uma análise superficial parecer inocente ou edulcorada era, ao propor um desarmamento contínuo e multilateral, a um só tempo apelar ao sentido financeiro último da corrida armamentista, que esvaziava os cofres governamentais bem como geopoliticamente apelar a um novo tipo de corrida, a pacifista, que poderia ser usada como mão de manobra política para angariar seguidores e influência no complexo tabuleiro de xadrez da política europeia.

O texto engeliano trabalhava em uma dupla hélice, caso fosse aceito seu pleito ao Reichstag terse-ia travado a corrida armamentista evitando o horizonte da guerra total. Não obstante, sendo rechaçado, o que era o mais provável, restava o mérito de ter exposto o real papel dos exércitos, educando as massas contra o chauvinismo e o militarismo rasteiros.

Engels eram um defensor contumaz do serviço militar universal e da formação de milícias populares armadas em detrimento de um exército permanente. Tal formação seria capaz de preparar a 
revolução ao treinar os trabalhadores no uso de armas bem como mitigar a probabilidade de uma contrarrevolução ao acabar com a hierarquia formal de um exército permanente ligado aos ciclos do poder burguês, dizia ele:

Quanto mais trabalhadores são formados no uso de armas, melhor. O alistamento universal é o corolário necessário e natural do sufrágio universal; coloca o eleitor em condições de fazer cumprir suas decisões, com a arma na mão contra qualquer tentativa de golpe de Estado. (ENGELS; MARX, 1985, p. 67)

Dentre os mais notórios escritos militares de Engels está o seu O Pó e o Reno ${ }^{44}$. Urdido devido à ameaça de guerra entre a Áustria e a França pelas possessões italianas da Áustria em 1859, o trabalho de Engels foi peculiar por não ter como alvo um público operário nem socialista. Marx, ao discutir com Engels a estratégia de divulgação do panfleto, disse:

[...] deve primeiro aparecer anonimamente para que o público acredite que o autor seja um general eminente. $\mathrm{Na}$ segunda edição... você vai revelar sua identidade... e então será um triunfo para a nossa festa. (ENGELS; MARX, 1983, p.393)

Em visita a Alemanha dois anos depois, Marx relatou a Engels que seus escritos haviam sido lidos nos mais altos círculos militares, tanto em Berlim como em Viena, onde foram considerado como obra apócrifa de um general prussiano. ${ }^{45}$ O Pó e o Reno foi amplamente recebido nos círculos de estudiosos militares como uma análise científica da perspectiva militar. Seu grande trunfo era passar nas entrelinhas uma arguta crítica do Império Prussiano e do Francês bem como a veleidade de seus propósitos.

Em sua essência, o panfleto de Engels era uma crítica à suposição comum nos círculos militares alemães de que o Reno deveria ser defendido no Pó; isto é, o flanco ocidental da grande Alemanha (incluindo o da Áustria) no rio Reno deve ser defendido através de seu flanco sul "natural" no rio Pó, no norte da Itália. Desafiando esse argumento em seus próprios termos, Engels demonstra sua ausência de sentido na práxis e que, se generalizado, implicaria de igual monta que a França possuiria por sua vez um direito "natural" a todas as terras a oeste do Reno.

Destarte, antes de garantir uma suposta segurança alemã, tal argumento serviria para justificar qualquer agressão francesa. Ademais ele garantiria um ódio eterno de uma Itália sob a égide dos desmandos austríacos em detrimento de uma Itália aliada em caso de independência. Em seu ensaio subsequente, Savoia, Nice e Reno ${ }^{46}$, Engels nos desvela um intrincado panorama europeu onde o teatro de guerra entre França e Prússia (Alemanha) deve ser pensado na pluralidade do concerto entre os países europeus e sob a égide da solidariedade internacional, a qual garantia, na prática, uma maior segurança a todos os envolvidos.

A partir de 1848, ou seja, a partir da brutal derrota dos trabalhadores parisienses nas mãos da reação, Engels passou a perceber o fim último da revolução social na sua capacidade ou não de neutralizar o exército controlado pela burguesia. Se até os idos da década de 70 ele ainda podia vislumbrar a possibilidade de uma repetição da eclosão da revolução francesa de 1793, onde um exército enfraquecido por conflitos no exterior pudesse ser suplantado por revolucionários que se colocariam à frente da defesa interna da pátria, a Guerra Franco-Prussiana e a derrota da Comuna de Paris o fariam rever suas opções. Era preciso tomar o exército burguês a partir de dentro: 
O militarismo domina e engole a Europa. Porém, esse militarismo também carrega dentro de si o embrião de seu próprio declínio. A concorrência entre os estados individuais obriga-os, por um lado, a investir mais dinheiro a cada ano no exército, na frota, na artilharia, etc. (ou seja, a acelerar cada vez mais a bancarrota financeira); e, por outro lado, a levar mais e mais a sério o serviço militar universal, tornando assim, o que acaba familiarizando todo o povo com o uso das armas, capacitando-o, portanto, a impor, em certo momento, sua vontade contra os déspotas militares no comando. E este momento virá assim que a massa do povo - os trabalhadores rurais e urbanos bem como os camponeses - tiver uma vontade. É nesse ponto que o exército dos príncipes se converte em exército popular; a máquina deixa de fazer o serviço, o militarismo naufraga na dialética de seu próprio desenvolvimento... E isso significará detonar o militarismo e junto com ele todos os exércitos permanentes, a partir de dentro. (ENGELS, 2015, p.199-200)

A partir de então a tarefa de subjugar o exército burguês ultrapassa o campo puramente militar do combate corpo a corpo e se desvela enquanto tarefa de paulatina construção política. Quanto mais avançava o militarismo, quanto mais cresciam os exércitos, mais fundamental se tornava a influência dos socialistas sobre os mesmos para a boa consecução da revolução, algo que seria ferramental essencial para Lenin e para a Internacional Comunista. ${ }^{47}$

Nos últimos anos da vida de Engels, antes da completa capitulação do SPD e da II Internacional frente ao chauvinismo e ao reformismo, as coisas pareciam ir de vento em poupa vis a vis às tentativas ditas "legalistas" de um crescimento do setor socialista por "dentro" das instituições do Estado burguês, as quais poderiam ser usadas para alavancar as lutas dos trabalhadores contra essas próprias instituições, sem jamais se olvidar a necessidade última de uma ruptura revolucionária violenta. Nas palavras do próprio Engels:

O tempo dos ataques surpresa, das revoluções realizadas por pequenas minorias conscientes sob a cabeça das massas sem consciência, é passado. Onde se trata de uma transformação completa da organização social, as próprias massas também devem estar envolvidas, devem elas mesmas já ter compreendido o que está em jogo, pelo que lutam de corpo e alma [...] Mas para que as massas possam entender o que deve ser feito, é necessário um trabalho longo e persistente [...] Em toda parte o exemplo alemão de utilizar o sufrágio, de conquistar todos os cargos acessíveis a nós, foi imitado; em todos os lugares, o lançamento despreparado de um ataque foi relegado para segundo plano. Manter esse crescimento em andamento sem interrupção até que fique além do controle do próprio sistema governamental vigente, para não desperdiçar essas tropas de choque diariamente crescentes em escaramuças de vanguarda, mas mantê-las intactas até o dia decisivo, essa é nossa principal tarefa. (ENGELS; MARX, 1990, p.520)

Nesse sentido, o que o General de Marx propugna não é o abandono da luta e o reformismo como algumas vezes depois de selado seu caixão fora covardemente acusado. Antes pelo contrário, notório conhecedor de tática, Engels mostra a necessidade de se travar uma guerra de posições, uma preparação consciente, para o momento crítico onde finalmente a guerra de manobras voltaria ser definitiva para o confronto final.

\section{Conclusão}

Se o partido dos trabalhadores quisesse ter uma perspectiva independente sobre a política, era necessária uma perspectiva independente sobre a guerra. Este projeto foi admiravelmente realizado desde 1848 por meio de uma análise da inter-relação entre os vários impérios europeus e a posição do movimento dos trabalhadores nele. Posteriormente, em ensaios como O Pó e o Reno, Engels fez tudo a seu alcance para 
minar os argumentos dos militaristas, montando uma poderosa crítica imanente de sua argumentos. Isto fora feito ao mesmo tempo em que articulava uma estratégia paralela para o movimento operário. Em um registro diferente, nos ensaios que escreveu para os socialistas e para a audiência da classe trabalhadora sobre este assunto, ele viu a participação em eleições parlamentares junto com o apoio ao alistamento universal como dois lados da ampla luta para lançar as bases para o desafio proletário ao poder do Estado que Lenin tão bem articularia na Rússia duas décadas após sua morte.

Engels foi um homem de uma erudição enciclopédica. Seu artigo para a New American Cyclopaedia ${ }^{48}$ cita desde Asclepiodotus e Eliano o Estrategista até análises sobre a recém-terminada Guerra Civil estadunidense. Porém, muito mais do que o rol taxativo de fontes ou as efemérides colecionadas em seus diversos escritos, o que rende a Engels um nome no panteão dos grandes estrategistas e analistas da História Militar é seu método. Fosse na análise da eclosão de conflitos locais, fosse na análise das totalidades do movimento do real, o que sempre pautou a obra engeliana, militar e política, foi o horizonte científico do socialismo e como instrumentalizar a materialidade da práxis para a consecução da revolução proletária.

\section{Referências}

ACHCAR, Gilbert. Engels, Theorist of War, Theorist of Revolution, in: International Socialism, 2002, 97.2, acessado em: http://pubs.socialistreviewindex.org.uk/isj97/achcar.htm

AGAMBEN, Giorgio. Homo sacer: O poder soberano e a vida nua. Belo Horizonte, Editora UFMG, 2000.

AGAMBEN, Giorgio. Meios sem fim: notas sobre a política. Belo Horizonte: Autêntica, 2015.

ANFRA, Douglas Rogério. Friedrich Engels: Guerra e Política. Uma investigação sobre a análise marxista da guerra e das organizações militares.2013. Orientador: Paulo Eduardo Arantes. 231pgs. Dissertação de Mestrado. São Paulo: USP, 2013.

ARON, Raymond. Clausewitz: Philosopher of War. Londres: RKP, 1983.

ARON, Raymond. Pensar a Guerra: Clausewitz. Vol. II A Era Planetária. Brasília: Edunb, 1986.

BAKH, Irene; FEDOSEYEV, P.N e STEPANOVA, Yevgenia. Karl Marx: A Biography. Moscou: Progress Publishers, 1977.

BERGER, M. Engels, Armies and Revolution. Hamden: Archon Books, 1977.

BLACKLEDGE, Paul. War and Revolution: Friedrich Engels as a Military and Political Thinker. In: War \& Society, 2019, 38:2, 81-97, DOI: 10.1080/07292473.2019.1566981

BUONICORE, Augusto C. (2013), "Engels diante de Marx: o segundo violino". In.: FUNDAÇ̃̃O Maurício Grabois. Publicado em 05 de agosto de 2013. Disponível em: Acessado em 29 de julho de 2015.

CARVER, T. Friedrich Engels: His Life and Thought. Londres: MacMillan, 1989.

CLAUSEWITZ, Carl Von. On War. Nova Jersey: Princeton University Press, 1984.

COGGIOLA, Osvaldo. Engels: O Segundo Violino. São Paulo: Xamã, 1995.

COUTINHO, Carlos Nelson. O Estruturalismo e a Miséria da Razão. São Paulo: Expressão Popular, 2017.

DRAPER, Hal. The Marx-Engels Chronicle: A Day-by-Day Chronology of Marx and Engels' Life and Activity. Nova York: Schocken Books, 1985. 
DRAPER, Hall; HABEKERN, E. Karl Marx's Theory of Revolution. Vol. 5: War and Revolution. Nova York: Monthly Review Press, 2005.

DROZ, Jacques. (ed). História General del Socialismo. De los origenes hasta 1875. Barcelona: Destino, 1976.

ENGELS, Friedrich; LAFARGUE, Paul. Correspondence. Vol 2. Moscou: Foreign Languages Publishing House, 1960.

ENGELS, Friedrich; MARX, Karl; LENIN, Vladimir. Escritos Militares. São Paulo: Global Editora, 1981.

ENGELS, Friedrich; MARX, Karl. A Ideologia Alemã. São Paulo: Boitempo, 2007.

ENGELS, Friedrich; MARX, Karl. A Sagrada Família. São Paulo: Boitempo, 2003.

ENGELS, Friedrich; MARX, Karl. Collected Works (MECW). Vol. 10. 1849-1851. Londres: Lawrence \& Wishart, 1978.

ENGELS, Friedrich; MARX, Karl. Collected Works (MECW). Vol. 16. 1858-1860. Londres: Lawrence \& Wishart, 1978.

ENGELS, Friedrich; MARX, Karl. Collected Works (MECW). Vol. 2. 1838-1842. Londres: Lawrence \& Wishart, 1975

ENGELS, Friedrich; MARX, Karl. Collected Works (MECW). Vol. 20. 1864-1868. Londres: Lawrence \& Wishart, 1985

ENGELS, Friedrich; MARX, Karl. Collected Works (MECW). Vol. 22. 1870-1871 - Londres: Lawrence \& Wishart, 1986.

ENGELS, Friedrich; MARX, Karl. Collected Works (MECW). Vol. 24. 1874-1883. Londres: Lawrence \& Wishart, 1989.

ENGELS, Friedrich; MARX, Karl. Collected Works (MECW). Vol. 26. 1882-1889 - Londres: Lawrence \& Wishart, 1986.

ENGELS, Friedrich; MARX, Karl. Collected Works (MECW). Vol. 27. 1890-1895 - Londres: Lawrence \& Wishart, 1990.

ENGELS, Friedrich; MARX, Karl. Collected Works (MECW). Vol. 3. 1843(MAR)-1844(AGO). Londres: Lawrence \& Wishart, 1975.

ENGELS, Friedrich; MARX, Karl. Collected Works (MECW). Vol. 38. 1844-1851 - Letters. Londres: Lawrence \& Wishart, 1982.

ENGELS, Friedrich; MARX, Karl. Collected Works (MECW). Vol. 4. 1844-1845. Londres: Lawrence \& Wishart, 1975.

ENGELS, Friedrich; MARX, Karl. Collected Works (MECW). Vol. 40. 1856-1859 - Letters. Londres: Lawrence \& Wishart, 1983.

ENGELS, Friedrich; MARX, Karl. Collected Works (MECW). Vol. 46. 1880-1883 - Letters. Londres: Lawrence \& Wishart, 1992.

ENGELS, Friedrich; MARX, Karl. Collected Works (MECW). Vol. 47. 1883-1886 - Letters. Londres: Lawrence \& Wishart, 1995.

ENGELS, Friedrich; MARX, Karl. Collected Works (MECW). Vol. 8. 1848-1849. Londres: Lawrence \& Wishart, 2010

ENGELS, Friedrich; MARX, Karl. Collected Works (MECW). Vol. 9. 1849. Londres: Lawrence \& Wishart, 1977.

ENGELS, Friedrich; MARX, Karl. Manifesto Comunista. São Paulo: Boitempo, 1998.

ENGELS, Friedrich. A Situação da Classe Trabalhadora na Inglaterra. São Paulo: Boitempo, 2008.

Germinal: Marxismo e Educação em Debate, Salvador, v. 12, n. 3, p. 186-202, nov. 2020. ISSN: 2175-5604 
ENGELS, Friedrich. Anti-Dühring. São Paulo: Boitempo, 2015.

ENGELS, Friedrich. Temas Militares. Buenos Aires: Ediciones Estudio, 1966.

GALLIE, W.B. Philosophers of Peace and War. Cambridge: Cambridge University Press, 1978.

GAT, Azar. A History of Military Thought. From Enlightment to the Cold War. Oxford: Oxford University Press, 2001.

GEMKOW, Heinrich et alli. Frederick Engels: A Biography. Dresden: Verlag Zeit im Bild, 1972.

HUNLEY, J.D. The Life and Thought of Friedrich Engels. New Haven: Yale University Press, 1991.

HUNT, Tristram. Comunista de Casaca. Rio de Janeiro: Editora Record, 2010.

HUNT, Tristram. Marx's General. New York: Henry Holt \& Co, 2009.

JONES, Gareth S. Retrato de Engels. In: HOBSBAWN, Eric. J et alli. História do Marxismo Vol. I. Rio de Janeiro: Paz e Terra, 1983.

KITCHEN, M. Friedrich Engels' Theory of War. In: Military Affairs, 41 (1977).

LENIN, Vladimir. Collected Works. Vol 31. Moscou: Progress Publishers, 1965.

LENIN, Vladimir. Collected Works. Vol. 2. Moscou: Progress Publishers, 1972.

LEVINE, N. The Tragic Deception: Marx Contra Engels. Oxford: Clio Press, 1975.

LOSURDO, Domenico. Como nasceu e como morreu o Marxismo Ocidental. BLOG DA

BOITEMPO. Disponível em: https://blogdaboitempo.com.br/2018/06/29/losurdo-como-nasceu-ecomo-morreu-o-marxismo-ocidental/. Publicado em 29 de jun. de 2018 (b). Acessado em 20 de set. de 2020.

LOSURDO, Domenico. Guerra e Revolução. São Paulo: Boitempo, 2017.

LOSURDO, Domenico. O Marxismo Ocidental. São Paulo: Boitempo, 2018.

LOUREIRO, Isabel (org.). Rosa Luxemburgo e o Protagonismo das Lutas de Massa. São Paulo: Expressão Popular, 2018.

LÖWY, Michael. A Teoria da Revolução no Jovem Marx. São Paulo: Boitempo, 2012.

LUXEMBURGO, Rosa. Oeuvres II. Écrits Politiques 1917-1918. Paris: François Maspero, 1971.

MARCUS, Steven. Engels, Manchester and the Working Class. Londres: Weidenfeld and Nicolson, 1974.

MAYER, Gustav. Friedrich Engels: Una Biografia. Cidade do México: Fondo de Cultura Economica, 1978.

NEUMAN, S; VON HAGEN, M. 'Engels and Marx on Revolution, War, and the Army in Society,' apud PARET, P. Masters of Modern Strategy Oxford: Oxford University Press, 1986.

PARET, P. Masters of Modern Strategy Oxford: Oxford University Press, 1986.

RAPPORT, Mike. 1848: Year of Revolution. Nova York: Basic Books, 2008.

RIPLEY, George; DANA, Charles A (Eds). New American Cyclopaedia. Nova York: D. Appleton and Company, 1879.

WALLACH, Jehuda. Die Kriegslehre von Friedrich Engels. Frankfurt: Europäische Verlagsanstalt, 1968.

WALTZ, Kenneth. O Homem, O Estado e A Guerra. Rio de Janeiro: Martins Fontes, 2004.

WHITFIELD, Roy. Friedrich Engels in Manchester. Manchester: Working Class Movement Library, 1988. 
Notas:

1 Doutorando em História Social da Cultura na Universidade Federal de Minas Gerais (UFMG). Currículo Lattes: Orcid: http://orcid.org/0000-0001-5864-9046 E-mail: boldogor@gmail.com

2 Sobre uma crítica das relações entre o estruturalismo e o chamado "pós-estruturalismo" e a análise marxista da realidade, consultar COUTINHO, Carlos Nelson. O Estruturalismo e a Miséria da Razão. São Paulo: Expressão Popular, 2017.

3 Para uma crítica das relações entre o chamado pós-modernismo e o marxismo na contemporaneidade ver PERRY, Matt. Marxism and History. Nova York: Palgrave, 2002; especialmente o capítulo 7, Marxism and Postmodernism in History, p. 129-154.

${ }^{4}$ Diz-se marxismo ocidental aquele marxismo, principalmente acadêmico, produzido na Europa, mormente após o XX Congresso do PCUS onde o enfoque é dado principalmente nas discussões pequeno burguesas e academicistas das análises teóricas internas do próprio campo marxista (e ocidental) em detrimento da "denúncia das cláusulas macroscópicas de exclusão da liberdade liberal" (LOSURDO, 2018b). Ainda mais, "O marxismo ocidental, no entanto, concentrou-se quase exclusivamente nas "formas respeitáveis" do domínio burguês e capitalista. Após perder de vista a sorte que, em primeiro lugar, estava reservada aos povos coloniais e de origem colonial, a crítica do "socialismo real", embora absolutamente necessária, desembocou numa banal apologética liberal e numa liquidação indiferenciada da história do comunismo do século XX. (LOSURDO, 2018b). Sobre o tema ver LOSURDO, Domenico. O Marxismo Ocidental. São Paulo: Boitempo, 2018.

5 Para exemplos de trabalhos profundamente críticos à obra engeliana ver LEVINE, N. The Tragic Deception: Marx Contra Engels. Oxford: Clio Press, 1975; CARVER, T. Friedrich Engels: His Life and Thought. Londres: MacMillan, 1989. Mesmos estes trabalhos, dos quais discordamos de suas análises, ao falarem das obras militares de Engels tecem amplos elogios.

6 Para um trabalho mais focado na obra militar engeliana ver HUNT, Tristram. Marx's General. New York: Henry Holt \& Co, 2009.

7 Aludimos aqui à famosa tese 11 do $A d$ Feurbach de Karl Marx; “Os filósofos apenas interpretaram o mundo de maneiras diferentes; a questão, porém, é transformá-lo." (ENGELS, MARX, 2007, p.535). Tal mote se tornaria o farol a iluminar todas as pesquisas ulteriores de Marx e Engels. Compreender seus estudos militares fora deste escopo é, em última instância, falseá-los.

8 Brigada de Artilharia Doméstica, tradução nossa.

9 Para uma discussão sobre o Hegelianismo de Esquerda na Alemanha na década de 40 do século XIX ver HEINRICH, Michael. Karl Marx e o Nascimento da Sociedade Moderna. Vol. I. São Paulo: Boitempo, 2018. Especialmente o capítulo 3.

${ }^{10}$ Essa coletânea de artigos de Engels, mormente para o Telegraph für Deutschland e para o Morgenblatt für gebildete Leser, encontram-se disponíveis do segundo volume da Marx-Engels Collected Works.

11 Sobre o assunto ver LENIN, Vladmir. Friedrich Engels. In: LENIN, Vladmir. Collected Works. Vol. 2. Moscou: Progress Publishers, 1972, p.15-28.

12 A Rheinische Zeitung, em português Gazeta Renana, foi um jornal fundado em janeiro de 1842 na cidade de Colônia. A partir de um começo de caráter reformista e uma filiação pró-democrática em oposição ao autoritarismo prussiano, o jornal foi cada vez mais aderindo a uma posição democrata radical, tendo vários de seus contribuidores tendo abraçado abertamente o socialismo. Dentre os grandes nomes que passaram pelo jornal merecem destaque, além dos de Karl Marx, que foi seu editor, e Friedrich Engels, cujos artigos publicados na Rheinische depois viriam a compor sua clássica obra $A$ situação da classe trabalhadora na Inglaterra, Max Stirner, Moses Hess entre outros. Desde o final de 1842 o jornal passou a ser cada vez mais perseguido e censurado pelo governo prussiano até seu fechamento em março de 1843. Sobre o período ver DRAPER, Hal. The Marx-Engels Chronicle: A Day-by-Day Chronology of Marx and Engels' Life and Activity. Nova York: Schocken Books, 1985 e LÖWY, Michael. A Teoria da Revolução no Jovem Marx. São Paulo: Boitempo, 2012, especialmente o capítulo I.

${ }^{13}$ GEMKOW, Heinrich et alli. Frederick Engels: A Biography. Dresden: Verlag Zeit im Bild, 1972, p. 53.

${ }^{14}$ Sobre os dois períodos que Engels viveu em Manchester ver MARCUS, Steven. Engels, Manchester and the Working Class. Londres: Weidenfeld and Nicolson, 1974 e WHITFIELD, Roy. Friedrich Engels in Manchester. Manchester: Working Class Movement Library, 1988.

15 A qual geraria uma série de artigos posteriormente publicados conjuntamente no hoje canônico $A$ Situação da Classe Trabalhadora na Inglaterra. Ver ENGELS, Friedrich. A Situação da Classe Trabalhadora na Inglaterra. São Paulo: Boitempo, 2008.

${ }_{16}$ Este texto, que impressionaria Karl Marx e o faria se debruçar sobre o estudo da economia política bem como sobre a percepção de que seria a classe trabalhadora, o proletariado, o responsável pela ruptura revolucionária, pode ser encontrado em ENGELS, Friedrich; MARX, Karl. Collected Works (MECW). Vol. 3. 1843(MAR)-1844(AGO). Londres: Lawrence \& Wishart, 1975, p.418-445.

17 Os Anais franco-alemães foram uma revista publicada em Paris por Arnold Ruge e Karl Marx como reação à censura do governo prussiano à Gazeta Renana. Os Anais tiveram uma única edição em fevereiro de 1844 devido à ruptura entre Ruge e Marx. Neles foram publicados além do texto mencionado de Engels, o ensaio de Marx Sobre a Questão Judaica bem como sua famosa Introdução à Crítica da Filosofia do Direito de Hegel. Sobre o assunto ver LÖWY, Michael. A Teoria da Revolução no Jovem Marx. São Paulo: Boitempo, 2012.

${ }^{18}$ Diz-se vida nua aquela existência privada das condições mínimas de humanidade onde tão somente a reprodução da própria vida é a condição única satisfeita pela mais abjeta miséria. O homem se torna ser sacrificial e a um só tempo indigno do próprio sacrifício. Sobre o conceito ver AGAMBEN, Giorgio. Meios sem fim: notas sobre a política. Belo Horizonte: Autêntica, 2015 e AGAMBEN, Giorgio. Homo sacer: O poder soberano e a vida nua. Belo Horizonte, Editora UFMG, 2000. 
${ }_{19}$ Nesse período Engels aprofunda seu ciclo de relações com os socialistas do crescente movimento cartista bem como com os seguidores do owenismo britânico, publicando uma profusão de artigos no The New Moral World, periódico de divulgação do owenismo; e no The Northern Star, periódico de orientação cartista. Para uma coletânea desses artigos ver ENGELS, Friedrich; MARX, Karl. Collected Works (MECW). Vol. 3. 1843(MAR)-1844(AGO). Londres: Lawrence \& Wishart, 1975 e ENGELS, Friedrich; MARX, Karl. Collected Works (MECW). Vol. 4. 1844-1845. Londres: Lawrence \& Wishart, 1975.

${ }^{20}$ Sobre o assunto ver MARX, Karl. Introduction to the French Edition of Engels' Socialism: Utopian and Scientific in: ENGELS, Friedrich; MARX, Karl. Collected Works (MECW). Vol. 24. 1874-1883. Londres: Lawrence \& Wishart, 1989, p.335

${ }^{21}$ Sobre o assunto ver BAKH, Irene; FEDOSEYEV, P.N e STEPANOVA, Yevgenia. Karl Marx: A Biography. Moscou: Progress Publishers, 1977, p.41-42,49.

22 Sobre o assunto ver BAKH, Irene; FEDOSEYEV, P.N e STEPANOVA, Yevgenia. Op.cit. p.82-83.

${ }^{23}$ ENGELS, Friedrich; MARX, Karl. A Ideologia Alemã. São Paulo: Boitempo, 2007.

${ }^{24}$ Sobre o assunto ver BAKH, Irene; FEDOSEYEV, P.N e STEPANOVA, Yevgenia. Op.cit. p.60.

${ }^{25}$ A carta se encontra na íntegra em MARX, Karl. Letter from Marx to Ruge. In: ENGELS, Friedrich; MARX, Karl. Collected Works (MECW). Vol. 38. 1844-1851 - Letters. Londres: Lawrence \& Wishart, 1982, p.15.

${ }^{26}$ GEMKOW, Heinrich et alli. op.cit, p.101.

27 O SAPD (Sozialdemokratische Arbeiterpartei Deutschlands) seria o antecessor do SPD. Fundado no ano de 1869 em Eisenach, congregaria elementos avançados do socialismo na Alemanha. Sobre o assunto ver DROZ, Jacques. (ed). Historia General del Socialismo. De los origenes hasta 1875. Barcelona: Destino, 1976.

${ }^{28}$ ENGELS, Friedrich; MARX, Karl. Manifesto Comunista. São Paulo: Boitempo, 1998.

29 O primeiro deles, The Magyar Struggle, pode ser encontrado em ENGELS, Friedrich. The magyar struggle. In ENGELS, Friedrich; MARX, Karl. Collected Works (MECW). Vol. 8. 1848-1849. Londres: Lawrence \& Wishart, 2010, p.227-238.

30 Os artigos podem ser vistos em ENGELS, Friedrich; MARX, Karl. Collected Works (MECW). Vol. 8. 1848-1849. Londres: Lawrence \& Wishart, 2010, p.451-480 e ENGELS, Friedrich; MARX, Karl. Collected Works (MECW). Vol. 9. 1849. Londres: Lawrence \& Wishart, 1977, p.9-463.

${ }^{31}$ Sobre a participação de Engels na luta revolucionária alemã ver RAPPORT, Mike. 1848: Year of Revolution. Nova York: Basic Books, 2008, p.342 e seguintes.

32 Um relato desse período pode ser encontrado em GEMKOW, Heinrich et alli. op.cit, p.202-210; um relato da pena do próprio Engels em ENGELS, Friedrich. Letter from Engels to Jenny Marx (25 de julho de 1849) in: ENGELS, Friedrich; MARX, Karl. Collected Works (MECW). Vol. 38. 1844-1851 - Letters. Londres: Lawrence \& Wishart, 1982, p.202-204.

33 Os artigos conforme foram publicados nos números 1,2 e 3 da Neue Rheinische Zeitung podem ser vistos em ENGELS, Friedrich. The campaign for the german imperial constitution in: ENGELS, Friedrich; MARX, Karl. Collected Works (MECW). Vol. 10. 1849-1851. Londres: Lawrence \& Wishart, 1978, p.147-239.

34 Sobre esforços mais compreensivos de se estudar a obra militar engeliana, destaca-se ainda hoje o livro de Jehuda Wallach. Ver WALLACH, Jehuda. Die Kriegslehre von Friedrich Engels. Frankfurt: Europäische Verlagsanstalt, 1968. Dentre os esforços nacionais vale notar o trabalho de ANFRA, Douglas Rogério. Friedrich Engels: Guerra e Política. Uma investigação sobre a análise marxista da guerra e das organizações militares.2013. Orientador: Paulo Eduardo Arantes. 231pgs. Dissertação de Mestrado. São Paulo: USP, 2013.

35 O Plano Schlieffen foi o plano militar aplicado pelo exército alemão no começo da primeira guerra mundial. Seu nome provém do chefe do Estado-Maior alemão entre 1892 e 1906 Alfred von Schlieffen, O plano deveria resolver a questão da guerra em dois frontes, a saber, uma ocidental contra a França e possivelmente o Reino Unido e outra oriental contra a Rússia. A ideia central que era obter uma vitória rápida no front ocidental e migrar as forças para o front oriental falhou e o plano foi abandonado. Sobre o assunto ver KEEGAN, J. The First World War. Nova York: Random House, 1998.

36 A referência é uma paráfrase a seguinte frase de Engels em seu Anti-Dübring "[...] tanto que hoje em dia é quase a regra um navio não atender às exigências, já estar antiquado, antes de sair do estaleiro" (2015, p.201). Onde Engels demonstra o desenvolvimento desigual das tecnologias militares e como as mesmas se tornam um escoadouro de dinheiro dos cofres públicos que levava os Estados europeus rumo à guerra ou a bancarrota.

${ }^{37}$ Sobre o assunto ver GINZBURG, Carlos. Sinais: raízes de um paradigma indiciário. In: GINZBURG, Carlos. Mitos, Emblemas, Sinais. São Paulo: Cia das Letras, 1989, p.143-179.

38 Sobre o assunto ver BERGER, M. Engels, Armies and Revolution. Hamden: Archon Books, 1977.

${ }^{39}$ ENGELS, Friedrich. Socialism in Germany. In: ENGELS, Friedrich; MARX, Karl. Collected Works (MECW). Vol. 27. 18901895 - Londres: Lawrence \& Wishart, 1990, p.235-250.

40 Referência à clássica frase de Rosa Luxemburgo "a social-democracia não é mais do que um cadáver fétido" em LUXEMBURGO, Rosa. Oeuvres II. Écrits Politiques 1917-1918. Paris: François Maspero, 1971, p. 101.

${ }^{41}$ LOUREIRO, Isabel (org.). Rosa Luxemburgo e o Protagonismo das Lutas de Massa. São Paulo: Expressão Popular, 2018, p.125-150.

42 Publicado originalmente em russo em outubro de 1916 e posteriormente traduzido por Victor Serge. O texto pode ser encontrado em LENIN, Vladmir; ZINOVIEV, Grigory. Contre le courant. Vol II. Paris: Bureau d'éditions, de diffusion et publicité, 1927, p.139-176.

${ }^{43}$ Tradução inédita para o português feita por nós se encontra no prelo e foi fornecida para publicação no presente dossiê sobre Engels. Para a tradução em inglês ver ENGELS, Friedrich. Can Europe Disarm. In: ENGELS, Friedrich; MARX, Karl. Collected Works (MECW). Vol. 27. 1890-1895 - Londres: Lawrence \& Wishart, 1990, p.367-393.

Germinal: Marxismo e Educação em Debate, Salvador, v. 12, n. 3, p. 186-202, nov. 2020. ISSN: 2175-5604 
${ }^{44}$ ENGELS, Friedrich. Po and Rhine. In: ENGELS, Friedrich; MARX, Karl. Collected Works (MECW). Vol. 16. 1858-1860. Londres: Lawrence \& Wishart, 1978, p. 211-255. Este texto, traduzido pela primeira vez em português, encontra-se no prelo em CARVALHO, João; LANDI, Gabriel e VASCONCELOS, Euclides. Engels: escritos militares. São Paulo: Baioneta/ICP, 2020.

${ }^{45}$ MARX, Karl. Letter to Engels., 7 May 1861. In: ENGELS, Friedrich; MARX, Karl. Collected Works (MECW). Vol. 40. 18561859 - Letters. Londres: Lawrence \& Wishart, 1983.

46 ENGELS, Friedrich. Savoy, Nice and Rhine. ENGELS, Friedrich; MARX, Karl. Collected Works (MECW). Vol. 16. 18581860. Londres: Lawrence \& Wishart, 1978. P. 569-610.

47 Lembremo-nos aqui da quarta condição para a adesão à Internacional Comunista, qual fosse: "Propaganda sistemática e persistente bem como agitação deve ser conduzida junto às forças armadas e células comunistas devem ser formadas em cada unidade militar. Na sua maioria os comunistas terão que fazer esse trabalho na ilegalidade, a falha em conseguir fazê-lo seria equivalente a uma traição a seu dever revolucionário e incompatível com a associação à Terceira Internacional". LENIN, Vladimir et alli. Terms of Admission into Communist International. In: LENIN, Vladimir. Collected Works. Vol 31. Moscou: Progress Publishers, 1965- p.206-211.

48 ENGELS, Friedrich. Army In: RIPLEY, George; DANA, Charles A (Eds). New American Cyclopaedia. Nova York: D. Appleton and Company, 1879.

Recebido em: 02.10.2020

Aprovado em: 09.11.2020 